\title{
Second Life para Educação à Distância: uma experiência entre estudantes brasileiros e portugueses
}

\author{
Josete Maria Zimmer', Marco Antônio Vezzani ${ }^{2}$ \\ ${ }^{1}$ Grupo Alpha, Faculdade de Educação da Universidade de São Paulo (USP) \\ ${ }^{2}$ Instituto Federal de Santa Catarina (IFSC), Campus Chapecó-SC
}

jmzimmer@uol.com.br, marcoavezzani@gmail.br

\begin{abstract}
This article analyzes the potentials of Second Life (SL) in the context of Online Education. The authors present the results of four interviews chosen from those published in the Master's program in Educational and Multimedia Communication of the Open University of Portugal. They also sought orientation in two authors, one Portuguese and the other Brazilian, who defend SL and its possibilities related to teaching-learning issues. In this analysis, the present authors listed the important points, which they themselves observed in relation to this resource, and compared them with the experiences, which they have personally gone through as they worked with it, in order to establish their own, also Brazilian, vision of this resource.
\end{abstract}

Resumo. Este artigo pretende analisar as potencialidades do Second Life (SL) no contexto da Educação Online. Os autores apresentam os resultados referentes a quatro entrevistas escolhidas daquelas que foram disponibilizadas pelos participantes do Mestrado em Comunicação Educacional e Multimedia da Universidade Aberta de Portugal. Buscaram pautar-se nos relatos apresentados por dois autores, um português e outro brasileiro, que são defensores do SL e suas possibilidades para o ensinoaprendizagem. Nessa análise, elencaram os pontos importantes observados por eles mesmos a respeito dessa ferramenta, bem como traçaram um paralelo com as experiências vivenciadas pessoalmente em seu trabalho com ela, a fim de estabelecerem uma visão própria e brasileira.

\section{Introdução}

O momento atual parece encaminhar-se para um movimento de inclusão digital, ultrapassando anteriores interrogações sobre eventuais benefícios da utilização do computador na área da educação. As tecnologias digitais de informação e comunicação invadiram e continuam invadindo todos os espaços da vida cotidiana, o que representa grandes possibilidades de conexões entre agentes sociais e culturais em tempos e espaços diferentes por meio da internet. Neste novo contexto, a escola situa-se como espaço de interseção entre as narrativas tradicionais e as novas tecnologias. Para Pereira (2009), perguntar hoje se a aprendizagem melhora com os computadores é uma questão inadequada que induz a respostas incompletas. O que se pode afirmar é que, com a internet, tornou-se possível o encontro das inteligências neste contexto social e cultural, 
o qual é denominado por Lévy (1996) de "novos espaços, novas velocidades". Ou seja, o espaço virtual.

Assim, sabendo-se que a educação é complexa e que antigamente incluía apenas os diálogos entre educadores e educandos numa sala de aula tradicional, viu-se expandida para discussões síncronas e assíncronas com as novas tecnologias. E estas que por si só não ensinam, podem ser recursos poderosos como estratégias de ensino e para melhores resultados. Para os estudiosos e pesquisadores, Almeida e Valente (2011), o sucesso das tecnologias digitais de informação e comunicação dependerá em muito da fundamentação pedagógica em que se sustenta. É esse cenário que será apresentado nesta experiência educacional baseada na interação com o uso do Second Life (SL).

Inicialmente, apresenta-se ao leitor os princípios do SL, seguidos pela revisão teórica, com base em artigos como o de Mattar e Valente (2007). Posteriormente apresenta-se o objetivo, a metodologia utilizada e os procedimentos. E finalmente, uma breve discussão a respeito das potencialidades e dificuldades do uso do SL.

\section{Revisão da literatura}

Segundo Mattar e Valente (2007), o Second Life era apenas uma derivação de outro jogo denominado The Sims. Quando Philip Rosedale ${ }^{1}$ o criou em 2003, ele redesenhou e disponibilizou o jogo na Internet. A partir dai o jogo se popularizar, adotando duas características que lhe deram sustentabilidade: o conceito de propriedade intelectual e $o$ de uma moeda virtual. Nesse primeiro conceito, o SL tornou-se um fenômeno, e o autor afirma: "Não construí um jogo, mas uma nação", ou seja, uma vida virtual poderia ser tão fascinante quanto a vida real. No segundo conceito, foi criada uma moeda imaginária, o "linden dollar", que foi atrelada à cotação do dólar de verdade. Cada usuário poderia comprar lindens com seu cartão de crédito real e dentro do SL, as transações seriam realizadas com essa moeda e quem ganharia algo poderia fazer a troca da moeda no fim do dia. A Linden $\mathrm{Lab}^{2}$ ganha dinheiro vendendo terrenos virtuais vazios (ilhas). Desse modo, pode-se dizer que o SL é um mundo virtual 3D, habitado por avatares, e que a interação ocorre entre seus habitantes, objetos e conteúdos.

A primeira incursão pessoal no mundo virtual SL pelos estudantes foi a criação de um avatar, com orientações da professora de iniciação ao software. A componente curricular visava preparar os alunos do Mestrado em Comunicação Educacional e Multimedia para o Congresso Virtual sobre Walter Ong. Nele os grupos préestabelecidos apresentariam publicamente o seu trabalho, havendo lugares para debate. As apresentações dos grupos foram analisadas, comentadas e discutidas por todos, e cada equipe participante deveria estar preparada para moderar e animar as discussões sobre o trabalho, estimulando e respondendo às questões que lhe foram colocadas durante o Congresso (Quintas Mendes, 2009).

\footnotetext{
${ }^{1}$ Disponível em http://revistaepoca.globo.com/Revista/Epoca/0,,EDG76483-6012-459,00.html. Obtido em 25/05/2017.

${ }^{2}$ Vende plataformas virtuais.
} 


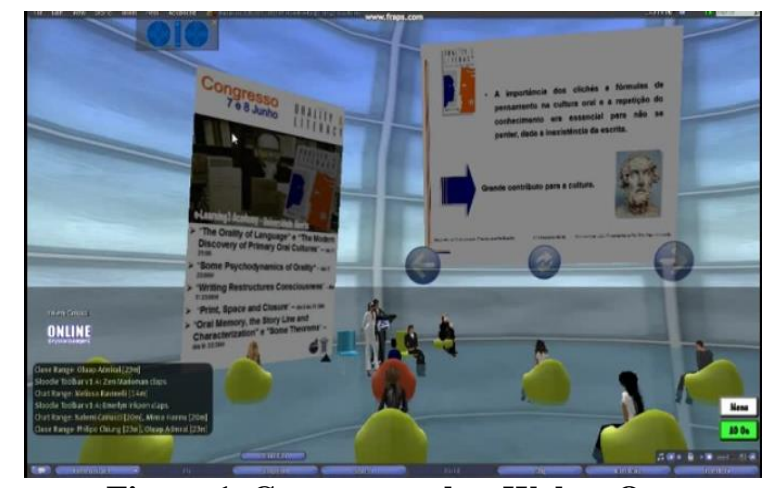

Figura 1. Congresso sobre Walter Ong

Conforme a orientadora Mendes (2009), o avatar é a representação gráfica de um utilizador. O termo "avatar" provém do Hindu, e do sânscrito significa a transfiguração do ser divino no corpo humano, a reencarnação de um Deus e a sua descida do céu à terra. Alguns avatares são cópias perfeitas dos seus donos. Ao se inscrever no SL, cada aluno criou um avatar dentre os vários que o programa apresentava. O programa permite um grau de personalização do avatar bastante versátil, a fim de deixá-lo com as características do seu representante. Os preços dos avatares no SL variam muito, dependendo do grau de semelhança com a realidade, havendo, inclusive, avatares com corpos exatamente como os reais. Há, no entanto, shapes (formas) e skins (peles) de muito boa qualidade em freeware.

O SL, como espaço de aprendizagem, chama atenção pela possibilidade de criação de locais lúdicos e ricos em várias dimensões. O grau de imersão e envolvimento dos alunos com o conteúdo do curso, com os colegas e com os professores é totalmente diferente dos ambientes tradicionais de ensino, tornando impossível sua reprodução em tais ambientes. Conforme Mattar (2007), a interatividade no SL é uma das maiores possibilidades educacionais. Os alunos deixam de ser consumidores passivos do aprendizado para se envolver na criação de suas próprias atividades. Os professores e os alunos podem construir os seus ambientes de aprendizagem a fim de que se possa vivenciar uma "viagem em busca do conhecimento". O ambiente motiva a colaboração por meio da exploração e descoberta e a interação social permite o desenvolvimento de atividades de aprendizagem formais e informais, em paralelo ou não, com as atividades de aprendizagem do mundo real.

\section{Objetivo}

Este estudo apresenta a trajetória de dois estudantes brasileiros durante seu percurso de aprendizagem no SL, a fim de explorar e apresentar um trabalho na disciplina de Comunicação Educacional no Curso de Mestrado em Comunicação Educacional e Multimedia da Universidade Aberta de Portugal. Bem como analisar as potencialidades e dificuldades observadas durante o percurso na exploração dessa ferramenta.

\section{Metodologia e procedimentos}

O ponto de partida do estudo foi a análise de quatro entrevistas realizadas conforme o "guião" enviado pelo professor. Este tratava sobre questões relacionadas à experiência dos alunos na utilização da plataforma SL, durante a preparação e participação do 
Congresso Virtual sobre Walter Ong. Para tanto, utilizou-se a metodologia de análise dos dados apresentados pelas respostas dos colegas de acordo com as perguntas do "guião" de entrevista enviado pelo Prof ${ }^{\circ}$. Dr. Antônio Quintas Mendes. Em seguida, buscou-se contextualizar essa análise sobre as afirmações dos autores Bettencourt e Abade (2008) e Mattar (2007), a fim de analisar os percursos, potencialidades e dificuldades do SL em situações de ensino-aprendizagem, propostas pelos autores. Finalmente, foram realizadas discussões e conclusões pessoais dentro de uma visão de dois estudantes brasileiros em experimentação com as novas tecnologias e ferramentas de educação à distância, como o Second Life, o Moodle e o mix Sloodle ${ }^{3}$.

Do guião de entrevista disponibilizado, algumas questões foram fundamentais para a elaboração deste trabalho. São elas: 1. Já tinhas ouvido falar do Second Life antes deste curso de Mestrado? 2. Já tinhas utilizado o Second Life antes deste Mestrado? 3. Achas que foi difícil moveres-te e navegares no SL? Aprende-se facilmente? Foi muito difícil no princípio e fácil no fim? Ou diria que é sempre difícil? 4. Como descreverias as tuas emoções e problemas ao entrares das primeiras vezes no SL? E como descreverias essas emoções e problemas perante a responsabilidade de fazeres um trabalho acadêmico concreto?

\section{Discussões e conclusões}

Conforme Mattar (2007), o SL vai além de um ambiente de aprendizagem virtual, no sentido do não real, mas possui o potencial de apresentar um ambiente "macro" composto de infinitos "microambientes", de uso em universidades, bibliotecas, museus, objetos, scripts, imagens, textos, sons, entre outros. Entre eles, destaca-se a possibilidade de interação aluno-aluno, na colaboração, motivação e envolvimento nas tarefas; a relação de proximidade aluno-professor para o esclarecimento de dúvidas; e o feedback automático das questões em geral.

No SL, os objetos podem ser criados, armazenados, compartilhados e disponibilizados para todos os envolvidos de um curso e ao mesmo tempo. Outro aspecto interessante é o grau de envolvimento e imersão dos alunos com o conteúdo, com os colegas e com os professores. Além disso, a interação síncrona e assíncrona dele é um diferencial em relação aos ambientes tradicionais de ensino, o que se torna uma rica plataforma para a Educação à Distância.

Outro aspecto da experiência vivenciada, é dar uma sugestão para todos os que pretendam utilizar a plataforma SL como meio de ensino, recurso educativo ou como meio de investigação. Antes de qualquer atividade, é essencial que alunos e professores busquem familiarização a fim de dominar os princípios básicos de navegação na plataforma SL. Entre os "conhecimentos básicos", pode-se destacar: a criação do avatar e suas características, a utilização do notecard ${ }^{4}$, domínio das setas de direção do teclado, dos controles de câmera, compreensão do que são objetos e as suas diferentes formas de utilização.

\footnotetext{
${ }^{3}$ Moodle é a plataforma de aprendizagem utilizada pela UAB. E Sloodle é o mix da plataforma Moodle com o Second Life.

${ }^{4}$ Ferramenta de texto.
} 
Embora observadas tantas possibilidades educacionais no SL, a plataforma ainda necessita aperfeiçoamento, tanto nas questões relacionadas ao hardware como na sua interface com outros programas. Por se tratar de uma ferramenta extremamente nova para os entrevistados, ressalta-se que sua utilização inicial foi difícil. Quanto ao estado emocional dos entrevistados, inicialmente houve momentos de devaneio, especialmente relacionados a problemas de conexão, muitas informações novas, e outras a serem internalizadas. Por isso, a transição da plataforma Moodle para a plataforma Sloodle não foi aceita com facilidade por todos. Entre as limitações destacam-se a necessidade de uma preparação muito pormenorizada, a necessidade de não perder tempo com deslocamento do avatar, e a utilização das ferramentas de comunicação.

Em relação à gestão do tempo nas aulas, conclui-se que o SL absorve muito dos participantes. Além disso, a incapacidade inicial dos alunos em lidar com o sistema causou alguns momentos de frustração.

Por fim, apesar das limitações do SL citadas pelos entrevistados, a busca pelo aprendizado e a responsabilidade nos trabalhos em grupo na plataforma possibilitaram maior interação entre colegas e professores, sendo uma experiência vivenciada com aprofundamento de propostas educativas advindas do Congresso Virtual.

\section{Referências}

Almeida, M. E. B; Valente, J. A. (2011). Tecnologias e currículo: trajetórias convergentes ou divergentes? São Paulo: Editora Paulus.

Amaral, É.; Avila, B. G.; Tarouco, L. (2012). Aspectos teóricos e práticos da implantação de um laboratório virtual no OpenSim. XXIII Simpósio Brasileiro de Informática na Educação, Rio de Janeiro, Brasil.

Bettencourt, T.; Abade, A. (2008), "Mundos Virtuais de Aprendizagem e de Ensino uma caracterização inicial." Obtido em 27 de maio de 2017 de https://cleobekkers.files.wordpress.com/2007/06/mundos_virtuais_tb_aa_siie2007.pdf

Lévy, P. (1996), O que é virtual?. $9^{a}$ Reimpressão (2009). São Paulo-Brasil: Editora 34.

Maia, C.; Mattar, J. (2007). ABC da EaD: A Educação a distância hoje. Ed. São Paulo: Pearson Prentice Hall.

Mattar, J. (2007). "O uso do Second Life como Ambiente Virtual de Aprendizagem." Obtido em 27 de maio de 2015, de http://www.comunidadesvirtuais.pro.br/seminario4/trab/jamn.pdf.

Mendes, A. Q. (2009). UAb de Portugal, Mestrado em Comunicação Educacional e Multimedia, disciplina de Comunicação e Educação.

Mendes, M. B. V. F. (2011). Processos de Comunicação e Aprendizagem E-learning. Uma experiência no Second Life. Dissertação de Mestrado em Pedagogia do e-Learning. Departamento de Educação a Distância da Universidade Aberta de Portugal, Lisboa.

Moreira, A., Barroso, M. P.; et al, (2009). SECOND LIFE: Criar/Produzir/Importar. Portugal - Fundação para Divulgação das Tecnologias da Informação.

Ong, W. J. (1991). Orality e Literacy: The Technologizing of the Word. Reimpressão, Routledge, London.

Pereira, Alda. (2009, março 08). "Aprendizagem e Tecnologias" Obtido em 25/05/2017 de https://pt.scribd.com/doc/14114557/Aprendizagem-e-Tecnologias. 